\title{
OS DIREITOS HUMANOS: UM OLHAR BOURDIEUSIANO
}

\author{
Denise Silva Vieira ${ }^{1}$ \\ José Querino Tavares Neto ${ }^{2}$
}

\section{Resumo}

O presente artigo analisa os direitos humanos a partir da visão do sociólogo e filósofo Pierre Bourdieu. Examina quais são os principais desafios dos direitos humanos na Contemporaneidade: o problema da efetividade, o problema da legitimidade e o problema da universalidade. Versa sobre o Direito brasileiro e os direitos humanos sob os aspectos dos problemas: do formalismo jurídico; da dissociação entre o formalismo jurídico e a realidade social; e da efetividade jurídica. Além disso, apresenta os direitos humanos enquanto um campo de disputa simbólica, o humanismo e uma perspectiva liberal conservadora.

Palavras-chave: campo; Direito brasileiro; Direitos humanos; humanismo; Pierre Bourdieu.

\section{HUMAN RIGHTS: A BOURDIEUSIAN PERSPECTIVE}

\begin{abstract}
This article will analyze human rights from the perspective of the sociologist and philosopher Pierre Bourdieu. It examines the main challenges of human rights in contemporary times: the problem of effectiveness, the problem of legitimacy and the problem of universality. It deals with Brazilian law and human rights under the aspects of the problems: legal formalism; the dissociation between legal formalism and social reality; and legal effectiveness. It also

\footnotetext{
* Mestranda do Programa de Pós-graduação em Direito e Políticas Públicas da Universidade Federal de Goiás UFG. Especialista em Negócios Financeiros pela Pontifícia Universidade Católica do Rio de Janeiro - PUC-RJ. Bacharela em Direito e em Administração em Comércio Exterior. Servidora do Ministério Público do Estado de Goiás, lotada na Corregedoria Nacional do Conselho Nacional do Ministério Público - CNMP. Endereço eletrônico: denisesv62d@gmail.com.

** Bolsista de Produtividade do CNPq. Pós-doutorado em Direito Constitucional pela Universidade de Coimbra com bolsa da Capes. Mestre em Sociologia pela Universidade Estadual de Campinas. Doutor em Sociologia pela Universidade Estadual Paulista Júlio de Mesquita Filho - UNESP. Doutor em Direito pela Pontifícia Universidade Católica do Paraná. Professor Associado da Faculdade de Direito da Universidade Federal de Goiás - UFG e da Pontifícia Universidade Católica de Goiás e Professor do Programa em Direito e Políticas Públicas da UFG. Endereço eletrônico: josequerinotavares@gmail.com.
} 
presents human rights as a field of symbolic dispute, humanism and a conservative liberal perspective.

Keywords: camp; Brazilian law; humanism; human rights; Pierre Bourdieu.

\section{Introdução}

O problema deste artigo é compreender os direitos humanos no âmbito do Brasil, particularmente no campo jurídico. Para tanto será desenvolvida uma breve análise histórica dos direitos humanos a partir da perspectiva de Pierre Bourdieu - com as categorias analíticas de campo, doxa e poder simbólico.

Assim, a proposta desse artigo é, por meio de uma metodologia bibliográfica tendo como referencial teórico as contribuições de Pierre Bourdieu, estabelecer a possibilidade de compreensão dos direitos humanos no âmbito do Brasil, particularmente no campo jurídico.

Pierre Bourdieu (1930-2002), filósofo de formação e um dos mais importantes sociólogos franceses, desenvolveu uma teoria tentando superar a dicotomia agente/ação/subjetivismo de Max Weber $(2004,2012)$ versus agência/instituição/objetivismo de Émile Durkheim (2009).

A perspectiva teórica de Bourdieu possibilita uma análise dos contextos intersubjetivos nos quais os valores, práticas e interações sociais são constituídos sem, contudo, deixar de lado outros aspectos não menos importantes na hipercomplexa dinâmica social.

Uma sociedade cuja dinâmica ultrapassa os sentidos tradicionais de análise exige uma perspectiva crítica que avance sobre sua complexidade e possibilite uma mais ampla compreensão dessa mesma dinâmica. É nesse sentido que Pierre Bourdieu parece aclarar tais aspectos hipercomplexos por meio de uma análise que não seleciona um aspecto da sociedade em detrimento de outro, em particular, em sociedades que se encaminham para que algoritmos extremamente sofisticados definam inclusive tendências outrora tidas como intrinsecamente subjetivas.

Essa afirmação também pode ser dita em relação aos direitos humanos. Com os avanços técnico-científicos e retrocessos políticos e sociais que ora divisamos em escala global fica cada vez mais difícil não questionar a importância de um campo tão significativo historicamente quanto o dos valores e, especialmente, dos valores orientados para a interação humana (direitos humanos), embora não só, uma vez que a própria existência humana, em escala mundial, está ameaçada devido ao desgaste do meio ambiente (biomas) nos quais e dos quais somos interdependentes.

O artigo tem como objetivo geral analisar a importância dos direitos humanos e os objetivos específicos são compreender, não exaustivamente, a dinâmica dos direitos humanos; a relevância, em particular no âmbito jurídico brasileiro; e a disputa simbólica constitutiva do campo de direitos humanos conforme Bourdieu.

\section{Um olhar a partir de Pierre Bourdieu sobre a problemática dos direitos humanos}


O conceito de campo, proposto por Pierre Bourdieu, é fundamental para a compreensão da dinâmica da formação dos direitos humanos em sua história, traduzido como um campo de disputas pela constituição de sujeitos plenos de direitos.

\subsection{Os principais desafios dos direitos humanos na Contemporaneidade}

Os direitos humanos se desenvolveram em um contexto histórico de transformações complexas e profundas que ainda exercem a sua influência, malgrado os seus detratores. Além disso, surgidos em meio às contradições dos séculos XVII e XVIII, notadamente, no âmbito das revoluções haitiana, estadunidense e francesa, os direitos humanos constituíram um amplo espectro de debates no transcorrer dos séculos seguintes (SANTOS, 2014).

Um dos problemas mais recorrentes para os direitos humanos desde as suas origens nos anos setecentos e oitocentos tem sido as condições de possibilidade de esses direitos tornarem-se efetivos ou garantidos pelos Estados-Nação. Embora importantes histórica e sociologicamente os direitos humanos, não raro, têm sido um palco de debates mais ou menos intensos sem, contudo, uma solução duradoura quanto à sua eficácia (SANTOS, 2014).

Devido à fragilidade quanto à consolidação institucional (jurídica) dos direitos humanos em escala global eles têm encontrado diversas vozes dissonantes ou contrárias, tanto quanto a sua existência enquanto princípios, tanto como na possibilidade de sua efetivação mesmo que fragilizada pela longa cadeia histórica de descaso para com aqueles e aquelas considerados como não humanos ou menos humanos conforme o contexto da época (SANTOS, 2014).

Para Bourdieu, todavia, um dos problemas fundamentais no âmbito das sociedades contemporâneas é o modo como elas se estruturam ao longo do tempo a fim de manterem determinadas estruturas simbólicas de poder e de dominação (BOURDIEU, 2000). Essas estruturas concorrem para a instabilidade de propostas ou movimentos mediante os quais segmentos da sociedade desejam ampliar direitos e condições vitais nessas mesmas sociedades (BOURDIEU, 2000).

Essas estruturas não surgiram de modo espontâneo nem são o resultado da vontade de um grupo específico. Surgiram ao longo do tempo envolvendo um intenso campo de disputas simbólicas, sociais, morais, econômicas e existenciais (BOURDIEU, 2000). Portanto, na perspectiva dos direitos humanos a consolidação de valores considerados fundamentais exige toda uma estrutura social, não raro, adversa às políticas tradicionais de poder/dominação tais quais Bourdieu tão bem demonstrou (BOURDIEU, 1987, 1999, 2000).

\section{$2.2 \mathrm{O}$ problema da efetividade no âmbito jurídico}

Um dos mais recorrentes desafios aos direitos humanos sempre foi como efetivá-los, como torná-los práticas concretas e não, meras abstrações, embora úteis principiologicamente.

$\mathrm{Se}$ as sociedades são estruturalmente hierarquizadas em torno da manutenção de determinadas práticas e ideologias sociais historicamente constituídas (statu quo), conforme bem o demonstra as pesquisas sociológicas desde o século XIX, então Bourdieu tem razão ao afirmar que as mudanças exigidas para uma transformação social não são da ordem do mero indivíduo nem mesmo de uma instituição específica, mas do conjunto das interações consideradas da sociedade (BOURDIEU, 1996, 2000). 


\section{$2.3 \mathrm{O}$ problema da legitimidade}

Uma vez garantida alguma efetividade segue-se então a questão da legitimidade a fim de se conseguir os consensos possíveis quanto à sua importância (HABERMAS, 2012). A questão da legitimidade nunca foi fácil. Desde o surgimento da Modernidade, com Thomas Hobbes (2005), Samuel Pufendorf (SAHD, 2007) e depois Jean-Jacques Rousseau (2012), para citar somente alguns pensadores, o debate jurídico em torno da legitimidade continua (DWORKIN, 2017).

Para Thomas Hobbes (2005) a garantia da legitimidade deveria ser a autoridade inconteste do monarca - cujos poderes estariam estabelecidos e regrados constitucionalmente. Para Samuel Pufendorf (2007), bem ao espírito da época racionalista na qual as ciências modernas tiveram suas origens; o Estado seria uma "somatória" das vontades individuais, uma espécie de resultante matemática necessária para que haja o "contrato social" - mais tarde analisado por John Locke e Rousseau, dentre outros (DWORKIN, 2014, 2017).

John Locke e Jean-Jacques Rousseau não compartilhavam da mesma perspectiva monarquista, com viés autoritário, de Hobbes. Ambos desenvolveram análises republicanas visando o tema da legitimidade, liberdade, soberania etc. (ESCRIVÃO FILHO; SOUSA JUNIOR, 2016).

No contexto das sociedades contemporâneas a legitimidade tem sido amplamente debatida devido aos desafios que ora as nações enfrentam por causa dos problemas que um mundo cada vez mais interligado ocasiona. E não só a legitimidade tem sido posta em causa, mas também outros princípios e valores considerados mais ou menos consolidados como o republicanismo, a democracia, a liberdade etc. (CARBONARI, 2020; CAILLÈ, 2006). Ademais, alguns autores defendem ainda um retorno à conformação abstrata das normas como condição de possibilidade para uma sociedade, pelo menos, mais estável (ESCRIVÃO FILHO; SOUSA JUNIOR, 2016).

Na perspectiva de Bourdieu, entretanto, não se trata de uma mera conformação às regras ou normas vigentes, mas, sobretudo, do modo como as sociedades constroem seus campos, suas doxas e hierarquiza seus poderes simbólicos. As perspectivas tradicionais insistiram muito no aspecto abstrato e formalista das normas como um dos aspectos centrais de suas proposições jurídicas para o controle no âmbito social (BOURDIEU, 1998, 2000, 2009).

\subsection{O problema da universalidade}

Talvez um dos maiores desafios filosóficos, sociais, históricos e científicos seja a manutenção do ideal de universalidade entendida não como Europa ou Estados Unidos, mas toda a humanidade. Ou seja, um conceito não-eurocêntrico e decolonial (SANTOS, 2014).

A universalidade tem sido posta em questão desde o final da Segunda Guerra Mundial. Isso porque os países do Eixo (Alemanha, Japão, Itália e aliados) utilizaram os meios mais sofisticados à época para exterminarem populações consideradas "inferiores" (HABERMAS, 2000). Desde Auschwitz que existe um desafio constante para o pensamento, conforme analisaram Primo Levi (2015), Theodor Adorno (2002) e Hannah Arendt (2016), em relação ao próprio conceito de civilização. A Europa era vista desde o século XVIII como 
o centro universal da difusão de ideias e valores. Uma concepção que será desafiada desde então por diversos estudos denominados pós-coloniais ou decoloniais (SANTOS, 2014).

De um centro privilegiado, econômico, social e técnico-científico, a Europa passará a enfrentar um questionamento constante quanto aos processos de colonização e seus impactos nos países ex-colonizados (SANTOS, 2014). Nesse mesmo sentido, Pierre Bourdieu, demonstrou a partir de seus estudos na Argélia os modos de dominação e exclusão social que a França estabeleceu naquele país, bem como as profundas rupturas nos processos de socialização (BOURDIEU, 1999, 2009).

Em resumo: como falar em valores universais, especialmente direitos humanos, quando os países autoproclamados "mais desenvolvidos e civilizados" estiveram na gênese das maiores barbáries do século XX? (SANTOS, 2014; GALTUNG, 1994; CARBONARI, 2020).

\section{O Direito brasileiro e os direitos humanos}

Os direitos humanos foram recepcionados pelo direito brasileiro de modo complexo e ambíguo. Compreender as condições pelas quais essa admissão ocorreu e os modos como se configura o âmbito dos direitos humanos na juridicidade brasileira é um dos desafios ao próprio desenvolvimento dos direitos enquanto tais.

\subsection{O problema do formalismo jurídico}

Kelsen definiu o direito contemporâneo como estritamente instrumental, ou seja, como uma forma de controle governamental. Um dos problemas de sua Teoria Pura do Direito foi o horizonte hermenêutico de o Direito distanciar-se, enquanto "ciência pura", de suas aplicações. Do ponto de vista epistemológico isso está correto. Contudo, os póskelsenianos seguiram por um outro caminho: um tipo de formalismo muito complicado conforme asseveram tanto Norberto Bobbio, um kelseniano stricto sensu, como outros críticos do positivismo jurídico "puro" (KELSEN, 2009; BOBBIO, 2017).

$\mathrm{Se}$ o formalismo jurídico fosse entendido em seu sentido específico, conforme defende Bobbio (2017) não haveria por que se preocupar. Entretanto, o formalismo avançou para além das fronteiras propostas por Kelsen e se tornou quase uma causa sui, ou seja, "um fim em si mesmo" (BOBBIO, 2017). De modo processual (instrumento) em um horizonte hermenêutico (análise) há um salto incomensurável. Porém, foi o que ocorreu em diversos aspectos no campo jurídico brasileiro (STRECK, 2020).

Se as sociedades desejam por meio do Direito alguma resolução de seus eventuais conflitos, então esse mesmo campo não pode, ou em tese não deveria, desconectar-se dos aspectos concretos dessa mesma sociedade demandante. Isso não é o que acontece. Há instrumentos jurídicos efetivos, contudo, em sociedades como a brasileira ficam restritos às classes com maior poder simbólico e capital social, muitas vezes conforme as estruturas historicamente constituídas, bem descritas por Bourdieu (2000).

3.2 O problema da dissociação entre o formalismo jurídico e a realidade social

De um ponto de vista sociológico jurídico separar o Direito das aspirações quanto a uma efetividade nas vidas dos indivíduos e/ou comunidades tem se afigurado como uma das 
formas de exclusão, de um lado, e a manutenção do statu quo, por outro lado (STRECK, 2020; BOURDIEU, 1998, 2000).

Qualquer sociedade tem como horizonte, pelo menos, ideal a manutenção de sua existência ao longo do tempo. Os conflitos e as demandas são constitutivos dessa sociedade como bem o demonstrou Max Weber $(2004,2012)$. O contratualismo filosófico jurídico parte da premissa de uma sociedade poder entrar em processo de destruição, razão pela qual o contrato seria um modo (ou na linguagem de Bourdieu, uma estrutura estruturante) por meio do qual essa sociedade tentasse resolver os seus conflitos sem recorrer necessariamente à violência em suas variadas formas (BOURDIEU, 1999, 2000; GILISSEN, 2014; NUSSBAUN, 2013).

Se essa sociedade não conseguir constituir mecanismos apropriados (suas estruturas estruturantes e/ou estruturadas) para a gestão dos conflitos imanentes à sociedade, então a tendência será um distanciamento entre os sujeitos dessa sociedade e esses mecanismos (ou estruturas) com o consequente enfraquecimento dessas mesmas estruturas ao longo do tempo. Ou seja, os direitos, outrora garantia da manutenção da sociedade, tornam-se enfraquecidos ou "anômicos" na teoria durkheimiana (GILISSEN, 2014).

O caso concreto brasileiro é preocupante porque desde a constituição da nação brasileira existe um hiato persistente entre o que os segmentos mais necessitados da sociedade desejam (e precisam) e o que o Estado (em geral sob o poder das classes subordinantes) responde (SANTOS, 2014).

\subsection{A efetividade jurídica em questão}

O jurista Lênio Streck tem sido um dos mais veementes críticos do Direito. Ele afirma que no Brasil as comunidades, geralmente as mais carentes, adotam uma perspectiva idealizada do Direito como uma forma de justiça, embora considerada hermética ou distante. De um ponto de vista constitucional toda vez que a lei falha como forma de mediação entre os conflitos sociais temos o horizonte denominado por Durkheim de anomia (STRECK, 2020; GILISSEN, 2014; SANTOS 2014).

\section{Os direitos humanos enquanto um campo de disputa simbólica}

Os direitos são construções históricas, sociais, políticas. Os direitos humanos, desde a sua constituição enquanto um campo de debates e proposições filosófico-jurídicas, têm se demonstrado como um horizonte de possibilidades sempre desafiadas pelos vieses reacionários (tradicionalistas) historicamente.

\subsection{A disputa pelos direitos humanos}

Desde a Antiguidade as sociedades debatem sobre normas e limites aos comportamentos permissíveis. Foi somente na Modernidade que um horizonte de concretude, embora frágil, surgiu em meio a turbulências sociais, com efeitos inesperados. Alguns 
exemplos disso são a Revolução Haitiana, a Revolução Estadunidense e a Revolução Francesa (CARBONARI, 2020).

O campo dos direitos humanos sempre foi, se se considerar o seu início histórico moderno, a partir, sobretudo, da Revolução Francesa, um palco de disputas acirradas por horizontes hermenêuticos de sentidos e significados com abrangência para os segmentos mais fragilizados historicamente nas sociedades (CARBONARI, 2020; SANTOS, 2014). Ou seja, os direitos humanos constituíram-se em um campo no qual as doxas tradicionais entrechocaram-se com as novas proposições da Modernidade, em que pese ter sido nessa mesma época que muitas atrocidades ímpares tenham ocorrido ao longo de sua história (CARBONARI, 2020; SANTOS, 2014; BOURDIEU, 2000).

A disputa pela definição de quais valores, quais significados, qual legitimidade, qual extensão ou pretensão de universalidade dos valores constitui um dos mais importantes embates sociais, filosóficos e jurídicos da Contemporaneidade (SANTOS, 2014).

Desse modo o campo dos direitos humanos se tornou uma arena de disputas entre as duas concepções clássicas de mundo - entendendo mundo aqui em seu sentido próprio, político, conforme bem o definiu Hannah Arendt (2016): à direita e à esquerda do espectro político mundial (BOBBIO, 2012). À direita desse espectro visando uma sociedade tradicional, ou seja, a manutenção do que consideram o ideal - passado; e à esquerda, visando uma sociedade progressista, ou seja, o que consideram enquanto tal - futuro (BOBBIO, 2012).

Na perspectiva bourdieusiana uma sociedade tradicional necessariamente enfrentará sempre o problema de se manter estática (uma impossibilidade histórica e fática). Embora fosse de uma perspectiva conservadora, Durkheim (2009) concordaria com Bourdieu. Para Durkheim toda sociedade mecânica (tradicional) tende inexoravelmente para orgânica (póstradicional) (BOURDIEU, 2003; CATANI, 2017).

4.2 O humanismo enquanto nova forma de significação do ser humano no mundo

O humanismo é uma invenção renascentista. O ser humano como o centro do cosmos, universo outrora habitado pela própria natureza imanente, tida como perfeita, e na Idade Média por um deus transcendente, foi uma verdadeira revolução copernicana na Filosofia como bem a definiu Kant em seu Crítica da razão pura (ARENDT, 2016; CARBONARI, 2020).

O humanismo renascentista possibilitou o surgimento das condições mediante as quais um campo outrora circunscrito no âmbito religioso se expandisse para além das fronteiras dos mosteiros e universidades católicas. Essa expansão está na origem da perspectiva liberal clássica, ou seja, um conjunto de princípios e valores que afirmam a dignidade humana, a liberdade como condição fundamental e o direito a ter direitos, embora historicamente com diversas contradições: mulheres, idosos, crianças, povos não europeus, não estavam incluídos no projeto liberal quando de sua formação (SANTOS, 2014; CARBONARI, 2020; ESCRIVÃO Filho; SOUSA JUNIOR, 2016).

Todavia, foi nesse horizonte hermenêutico denso e tenso que surgiram as condições de possibilidade para um debate que não cessou até os presentes dias. A busca pela expansão dos direitos para as minorias étnicas, de gênero etc. (CARBONARI, 2020; ESCRIVÃO FILHO; SOUSA JUNIOR, 2016). 


\subsection{A perspectiva liberal conservadora}

O liberalismo clássico surge no mesmo contexto das transformações que deram origem aos direitos humanos. Embora tenha se expandido ao longo da sua história como um campo de disputa pela construção intersubjetiva dos sujeitos de direito e tenha perdido muito da força transformadora originária (RAWLS, 2000).

A Europa a partir dos séculos XV e XVI passa a dominar a navegação e a expandir os seus territórios em busca de maiores vantagens econômicas e políticas internacionais. Em meio a esse processo turbulento surge toda uma série de novas ideias e técnicas que desafiarão os conceitos tradicionais herdados da Idade Média e da Antiguidade quanto ao conhecimento da vida, natureza, humanidade, sociedade etc. (HABERMAS, 2000).

Com a hegemonia dos países europeus: Portugal, Espanha, França, Inglaterra, Holanda, Alemanha e Bélgica, sobre diferentes povos, e o desenvolvimento maciço de novas tecnologias devido aos processos históricos de busca por expansão da produção de novas riquezas, irrompe a disputa pela legítima interpretação jurídica de quem seria ou não sujeito de direitos (SANTOS, 2014; CARBONARI, 2020).

A hegemonia europeia circunscreveu os ideais liberais nascentes à própria Europa. E, não obstante afirmasse a universalidade, não abrangeu uma miríade de povos com os quais manteve contato, malgrado, de forma violenta (SANTOS, 2014; BOURDIEU, 1999; CARBONARI, 2020).

O liberalismo clássico afirma o direito à liberdade como condição fundamental do ser humano, bem como o direito a ter direitos (RAWLS, 2000). No processo de desenvolvimento desse ideário, todavia, demonstrar-se-ia muito mais difícil vencer as velhas barreiras nacionalistas e identitárias nacionais a fim de uma universalização de fato e não apenas mitigada (HABERMAS, 2000; SANTOS, 2014).

\subsection{A perspectiva progressista}

O denominado campo político progressista é heterogêneo e comporta um espectro de amplo de perspectivas quanto ao que deva ser uma sociedade boa. De forma habitual, é equivocadamente confundido stricto sensu com o marxismo - outro campo não menos heterogêneo politicamente. Eos ipso um campo tanto externamente quanto internamente de disputas no que tange à "hegemonia da legítima interpretação" (RAWLS, 2000; BOURDIEU, 2000).

O campo progressista propõe políticas de inclusão social, diferindo não apenas quanto à efetivação da universalização dos direitos - um ponto dos mais importantes, mas quanto à consolidação dos direitos considerados fundamentais (direitos humanos) (RAWLS, 2000; HABERMAS, 2000).

O espectro progressista insiste na ideia de os direitos humanos serem não apenas um novo vocabulário (o "politicamente correto"), mas novas formas de socialização e convívio no âmbito das sociedades contemporâneas (HABERMAS, 2000; SANTOS, 2014; BOURDIEU, 1999, 2009; CAILLÉ, 2006).

\section{Considerações finais}


O presente artigo tem como pretensão não exaustiva a análise do desenvolvimento, dos direitos humanos ao longo de sua história e de sua importância no âmbito jurídico, notadamente brasileiro.

Procurou analisar os diversos obstáculos que os direitos humanos enfrentam para a sua efetivação e consolidação. Assim, perscrutou a efetividade, a legitimidade e a universalidade em uma perspectiva bourdieusiana, ou seja, conforme as categorias analíticas de campo, doxa e poder simbólico, propostas pelo sociólogo francês, Pierre Bourdieu.

Analisou brevemente o direito brasileiro no que se refere à consolidação dos direitos fundamentais e às dificuldades estruturais sistêmicas (ou estruturantes no dizer de Bourdieu) quanto a sua efetivação. Percorreu o problema do distanciamento formal e das demandas concretas sociais sempre mantendo no horizonte o risco da anomia - conforme a definiu o sociólogo francês, Émile Durkheim (2009) - como um enfraquecimento dos vínculos que sustentam quaisquer sociedades.

E, por fim, analisou também o horizonte hermenêutico histórico no qual os direitos humanos tornaram-se uma arena (ou campo) de debates intensos, a saber o liberalismo clássico e a disputa com o espectro progressista - desenvolvido em resposta ao enfraquecimento ou colonização (conforme Habermas assim o define) do liberalismo. Sempre mantendo em perspectiva que os direitos humanos são muito mais do que um discurso de boa consciência, mas toda uma nova possibilidade de socialização inclusiva visando ao convívio nas e das sociedades em um mundo cada vez mais interconectado e com indivíduos cada vez mais distantes e alienados, conforme o demonstrou o sociólogo alemão, Axel Honneth (2015, 2018).

\section{Referências bibliográficas}

ADORNO, Theodor W. Indústria cultural e sociedade. 5. ed. Rio de Janeiro: Paz e Terra, 2002. (Coleção Leitura). Disponível em:

https://edisciplinas.usp.br/pluginfile.php/4179826/mod_resource/content/1/IND\%C3\%9AST RIA\%20CULTURAL\%20E\%20SOCIEDADE.pdf. Acesso em: 31 mar. 2021.

ARENDT, Hannah. A condição humana. 13. ed. São Paulo: Forense Universitária, 2016.

BAUMAN, Zygmunt. Vida em fragmentos: sobre a ética pós-moderna. Rio de Janeiro: Zahar, 2011.

BERLIN, Isaiah. Estudos sobre a humanidade. Uma antologia de ensaios. São Paulo: Companhia das Letras, 2002.

BOBBIO, Norberto. Direita e esquerda: razões e significados de uma distinção política. 3 . ed. São Paulo: UNESP, 2012. 
2017. O positivismo jurídico: lições de Filosofia do Direito. 1. ed. São Paulo: Ícone,

BOURDIEU, Pierre. A dominação masculina. 1. ed. Rio de Janeiro: Bertrand Brasil, 1999.

A economia das trocas simbólicas. 1. ed. São Paulo: Perspectiva, 1987.

. Economia das trocas linguísticas. 2. ed. São Paulo: USP, 1998.

. O campo científico. In: ORTIZ, Renato (Org.) Pierre Bourdieu. Sociologia. São Paulo: Ática, 1994.

O poder simbólico. 3. ed. Rio de Janeiro: Bertrand Brasil, 2000.

O que falar quer dizer. 1. ed. Lisboa: Difel 82, 1998.

O senso prático. 1. ed. Petrópolis: Vozes, 2009.

Questões de sociologia. 1. ed. Lisboa: Fim de Século, 2003.

As regras da arte: gênese e estrutura do campo literário. São Paulo: Companhia das Letras, 1996.

BUCCI, Maria Paula Dallari et. al. Direitos humanos e políticas públicas. São Paulo: Pólis, 2001.

"Método e aplicações da abordagem Direito e Políticas Públicas". In Revista

Estudos Institucionais. v.5, n.3, p. 791-832, set./dez. 2019.

Políticas públicas e direito administrativo. In: Revista de Informação Legislativa, Brasília, a. 34, n.133, jan./mar.1997.

Revista de Direitos Humanos e Efetividade | e-ISSN: 2526-0022 | Encontro Virtual |

v. 7 | n. 1 | p. 139 - 153 | Jan/Jul. 2021. 
CARBONARI, Paulo César. A construção dos Direitos Humanos: uma breve leitura histórica de elementos para a compreensão da institucionalização dos direitos humanos no Brasil. In Rev. Eletrônica Portas, n. 0, p. 5-14, jun. 2007. Acesso em: 26 jul. 2020.

CAILLÉ, Alain et al. História argumentada da Filosofia Moral e Política: a felicidade e o útil. São Leopoldo: Unisinos, 2006.

CARDANO, Mario. Manual de pesquisa qualitativa: a contribuição da Teoria da Argumentação. Petrópolis: Vozes, 2017.

CATANI, Afrânio Mendes et al. Vocabulário Bourdieu. Belo Horizonte: Autêntica, 2017.

Corte Interamericana de Direitos Humanos. Disponível em:

https://www.cidh.oas.org/basicos/portugues/v.Estatuto.Corte.htm. Acesso em: 24 ago. 2020.

COUTINHO, Maria Fernanda Abreu. Pierre Bourdieu e a gênese do campo literário. In:

Revista de Letras, v.1, n. 25, 11, 2003.

CORTINA, Adelia. Ética mínima. São Paulo: Martins Fontes, 2009.

DELRUELLE, Edouard. Metamorfoses do sujeito: a ética filosófica de Sócrates a

Foucault. Lisboa: Instituto Piaget, 2004.

DURKHEIM, Émile. As regras do método sociológico. 9. ed. Lisboa: Editorial Presença, 2009. Disponível em: https://wp.ufpel.edu.br/franciscovargas/files/2018/05/As-Regras-DoMetodo-Sociologico-Emile-Durkheim.pdf. Acesso em: 04 abr. 2021.

DWORKIN, Ronald. A raposa e o porco-espinho: Justiça e valor. São Paulo: Martins Fontes, 2014.

Levando os direitos a sério. São Paulo: Martins Fontes, 2017. 
EPSTEIN, Lee; KING, Gary. Pesquisa empírica em direito - as regras de inferência. São Paulo: Direito GV, 2013 (livro eletrônico). Disponível em:

file:///D:/Pesquisa_empirica_em_direito.pdf. Acesso em: 29 ago. 2020.

ESCRIVÃO FILHO, Antonio; SOUSA JUNIOR, José Geraldo de. Para um Debate TeóricoConceitual e Político sobre Direitos Humanos. In: DELGADO, Ana Luisa (Org. et all).

Gestão de Políticas Públicas de Direitos Humanos Coletânea. $1^{\text {a }}$ ed. Brasília: Escola Nacional de Administração Pública ENAP, 2016-c, v.1, p. 45-117. (pdf)

GALTUNG, Johan. Direitos Humanos: uma nova perspectiva. Lisboa: Instituto Piaget, 1994.

GILISSEN, John. Introdução histórica ao direito. Lisboa: Fundação Calouste Gulbenkian, 1995. Curitiba: Clube dos Autores, 2014.

GUSTIN, Miracy Barbosa de Sousa; DIAS, Maria Teresa Fonseca. (Re)pensando a pesquisa jurídica: teoria e prática. 4 ed. Belo Horizonte: Del Rey, 2015.

HABERMAS, Jürgen. O discurso filosófico da Modernidade. 3. ed. Portugal: Dom Quixote, 2000.

Teoria do agir comunicativo. 2 volumes, São Paulo: Martins Fontes, 2012.

HELLER, Agnes. Ética general. Madrid: Centro de Estudios Constitucionales, 1995. Além da Justiça. Rio de Janeiro, 1998.

HOBBES, Thomas. Leviatã. São Paulo: Rideel, 2005.

HONNETH, Axel. O direito da liberdade. São Paulo: Martins Fontes, 2015. 
Reificação: um estudo de teoria do reconhecimento. São Paulo: UNESP, 2018.

HOOF, Stan Van. Ética da virtude. Rio de Janeiro: Vozes, 2013.

HURD, Heidi M. O combate moral. São Paulo: Martins Fontes, 2003.

KELSEN, Hans. Teoria Pura do Direito. SP: Martins Fontes, $8^{a}$ edição, 2009.

LAHIRE, Bernard. Le travail sociologique de Pierre Bourdieu : dettes et critiques. Paris : Éditions La Découverte, 1999.

LAMOUNIER, Gabriela Maciel. A Corte Interamericana de Direitos Humanos: estudo de casos contencioso. In: Caderno de Relações Internacionais, vol. 7, n. 12, p. 37-45, jan./jul. 2016. Acesso em: 27 jul. 2020.

LEVI, Primo. Assim foi Auschwitz: testemunhos 1945-1986. São Paulo: Companhia das Letras, 2015.

LOCKE, John. Segundo Tratado sobre Governo Civil. São Paulo: Edipro, 2014.

LÖWITH, Karl. De Hegel a Nietzsche: A ruptura revolucionária no pensamento do século XIX - Marx e Kierkegaard. São Paulo: UNESP, 2014.

MAGALHÃES, Breno Baía. Pluralismo constitucional interamericano: a leitura plural da Constituição de 1988 e o diálogo entre o Supremo Tribunal Federal e a Corte Interamericana de Direitos Humanos. (Tese de doutorado). Belém: UFPA, 2015. Disponível em:

http://repositorio.ufpa.br/jspui/bitstream/2011/7497/1/Tese_PluralismoConstitucionalIntramer icano.pdf. Acesso em: 27 jul. 2020.

MONTESQUIEU, Charles-Louis de Secondat. O espírito das leis. São Paulo: Martins Fontes, 1996. 
NUSSBAUM, Martha C. Fronteiras da Justiça: deficiência, nacionalidade, pertencimento e gênero. São Paulo: Martins Fontes, 2013.

ONU (Organização das Nações Unidas), Declaração Universal dos Direitos Humanos, 1948. Disponível em: https://nacoesunidas.org/direitoshumanos/declaracao/. Acesso em: 24 ago. 2020.

PINTO, Louis. Pierre Bourdieu e a Teoria do Mundo Social. Rio de Janeiro: FGV, 2000.

PUFENDORF, Samuel. Os deveres do homem e do cidadão de acordo com a lei natural. Rio de Janeiro: Toopbooks, 2007.

RAWLS, John. O liberalismo político. São Paulo: Ática, 2000.

RAWLS, John. Uma teoria da justiça. São Paulo: Martins Fontes, 2016.

ROUSSEAU, Jean-Jacques. Discours sur l'origine et les fondements de l'inégalité parmi les hommes. Les Classiques de la Philosophie - Livre de poche. Paris: Librairie Générale Française, 2013.

Du contrat social. Paris : Flammarion, 2012.

SAHD, Luiz Felipe Netto de Andrade e Silva. Teorias da lei natural: Pufendorf e Rousseau. In: XII Encontro de Filosofia da ANPOF - GT Filosofia e Direito, 2006, Salvador. São Paulo: Trans/Form/Ação [online]. 2007, vol. 30, n. 2, p. 219-234. Disponível em: http://www.scielo.br/pdf/trans/v30n2/a14v30n2.pdf. Acesso em: 31 mar 2021.

SANTOS, Boaventura de Sousa. E se Deus fosse um ativista dos direitos humanos. 2. ed. São Paulo: Cortez, 2014.

SPINOZA, Baruch. Ética. Minas Gerais: Autêntica, 2009.

STRECK, Lênio. Hermenêutica, Jurisdição e Decisão: diálogos com Lênio Streck. RS: Livraria do Advogado, 2. ed., 2020. 
TAVARES NETO, José Querino. As possibilidades de constituição de um Poder Judiciário Socioambiental a partir da teoria de Pierre Bourdieu. Curitiba, 2014. Tese (Doutorado em Direito) - Programa de Pós-Graduação em Direito, Pontifícia Universidade Católica do Paraná.

TAVARES NETO, José Querino; MEZZAROBA, Orides. O método enquanto pressuposto de pesquisa para o Direito: a contribuição de Pierre Bourdieu. Revista de Direito Brasileira, São Paulo, v. 15, n. 6, p. 116-132, set/dez. 2016. Acesso em: 26 jul. 2020.

TUGENDHAT, Ernst. Lições sobre Ética. 3. ed. Rio de Janeiro: Vozes, 1999.

WEBER, Max. Economia e sociedade: ação racional. v. 1 Brasília: Fundação Universidade de Brasília, 2012.

WEBER, Max. Economia e sociedade: fundamentos da sociologia compreensiva. v. 2 São Paulo: Fundação Universidade de Brasília, 2004.

WILLIAMS, Bernard. Moral: uma introdução à ética. São Paulo: Martins Fontes, 2005. 